\title{
Ocean Acidification and Protection under International Law from Negative Effects: A Burning Issue amongst a Sea of Regimes?
}

\author{
Yangmay Downing*
}

\begin{abstract}
Ocean acidification is a recently recognised phenomenon and, like climate change, is the consequence of increased anthropogenic carbon dioxide $\left(\mathrm{CO}_{2}\right)$ emissions. As the atmospheric concentration of $\mathrm{CO}_{2}$ rises, the oceans directly assimilate $\mathrm{CO}_{2}$ and automatically become more acidic. The phenomenon poses a huge concern for calcifying organisms such as shellfish, pteropods and corals. Any negative impacts caused to organisms at this level will have far-reaching consequences for biodiversity, food, employment and economic activity across the globe. The aim of this article is to examine two questions: first, whether the current international regulatory framework can provide adequate protection from the negative effects of ocean acidification, and if not, what can be done to better address this issue? Existing international regimes only tangentially address the issue and this may accordingly lead to suboptimal environmental protection. This paper concludes that a new protocol under the United Nations Framework Convention on Climate Change, that has a twin focus on ocean acidification and climate change, would provide the most appropriate step to avoid the negative effects associated with the phenomenon.
\end{abstract}

\section{Keywords}

Environmental law, law of the sea, climate change

LLM candidate, University of Auckland. The author thanks Dr David VanderZwaag for helpful comments on this research. 


\section{Introduction}

While natural systems have complex interactions that defy our attempts to impose crude jurisdictional and substantive boundaries, ${ }^{1}$ any ensuing disturbance to these systems can also defy the ambit of regulatory methods in place. This assertion can easily be demonstrated by ocean acidification. The negative effects of this phenomenon are not the exclusive preserve of any particular regime. $^{2}$ Instead, different aspects related to ocean acidification are addressed by a multitude of regimes, creating the risk that the issue may easily become sidelined.

The consequence of anthropogenic $\mathrm{CO}_{2}$ emissions on the atmosphere has received much attention. Anthropogenic climate change has been the topic of considerable discussion, and simultaneously, denial. The consequence of $\mathrm{CO}_{2}$ release on the oceans, on the other hand, has had a shorter history of attention and presents another different yet serious problem known as ocean acidification. This phenomenon constitutes a serious threat to the marine environment. There is little to deny about this straightforward chemical process: as the atmospheric concentration of $\mathrm{CO}_{2}$ rises, the oceans directly assimilate $\mathrm{CO}_{2}$ and automatically become more acidic. ${ }^{3}$

This paper will consider two questions. The first question is whether the current international regulatory framework can provide adequate protection from the negative effects of ocean acidification. The second question is: if this regulatory framework does not provide adequate protection, what else can be done to better address the issue?

In considering these questions, this paper does three things. First, it will provide an overview of the science of ocean acidification and the effect it has on marine biology and ecosystems. Secondly, it traces the international law and policy applicable to the issue, and examines the extent that these existing mechanisms can adequately address ocean acidification. Finally, this paper provides suggestions about ways international law could provide better protection from the negative effects of the phenomenon.

1 R Barnes, 'Fisheries and Marine Biodiversity' in M Fitzmaurice, D M Ong \& Panos Merkouris (eds) Research Handbook on International Environmental Law (2010) 542, 543.

2 'Regime' has been defined as 'a set of rules which apply to a particular place or activity', see: J R Fox, Dictionary of International and Comparative Law (1997) 267.

3 C Nelleman, S Hain \& J Alder, In Dead Water: Merging of Climate Change With Pollution, Over-harvest, and Infestations in the World's Fishing Grounds (2008) 36. 


\section{Ocean acidification}

Ocean acidification is a recently recognised phenomenon and, like climate change, is the consequence of increased anthropogenic carbon dioxide $\left(\mathrm{CO}_{2}\right)$ emissions. It has been defined as 'a reduction in the $\mathrm{pH}$ of the ocean over an extended period, typically decades or longer, caused primarily by the uptake of $\mathrm{CO}_{2}$ from the atmosphere. ${ }^{4}$ It can similarly be explained as a process whereby seawater becomes more acidic, when increasing amounts of anthropocentric $\mathrm{CO}_{2}$ from the atmosphere dissolve in seawater to create carbonic acid, which releases hydrogen ions. ${ }^{5}$ Measured as lower $\mathrm{pH}$, these hydrogen ions increase ocean acidity and reduce calcium carbonate ion saturation. ${ }^{6}$ The crucial result of this process is that when water is under-saturated in relation to calcium carbonate, the seawater becomes corrosive and calcifying organisms (organisms that build shells) will become increasingly prone to dissolution. ${ }^{7}$

At present, the global ocean is a major sink for anthropogenic $\mathrm{CO}_{2}$ emissions. It is estimated that the surface waters of the oceans have taken up about 25 per cent of the carbon generated by anthropogenic activities since $1800,{ }^{8}$ thereby altering seawater chemistry. ${ }^{9}$ The basic chemistry of seawater is changing on a scale unobserved within fossil records over at least twenty million years, and it is happening at 'an unprecedented rate not experienced in the last 65 million years. ${ }^{10}$ In its 2007 report, the Intergovernmental Panel on Climate Change (IPCC) noted that the $\mathrm{pH}$ of the surface ocean is already 0.1 units lower than in pre-industrial times. ${ }^{11}$ The IPCC also stated that, with projected $\mathrm{CO}_{2}$ rises through this century, ocean $\mathrm{pH}$ could decrease by 0.3 to 0.4 units meaning that ocean acidity could increase by 100 to 150 per cent by $2100 .{ }^{12}$

Buck and Folger note that gases, such as $\mathrm{CO}_{2}$, are generally less soluble

${ }^{4}$ J Gattuso \& L Hansson, 'Ocean Acidification: Background and History' in J Gattuso \& L Hansson (eds), Ocean Acidification (2011) 2.

5 E H Buck \& P Folger, 'Ocean Acidification' in S E Haffhold, Encyclopedia of Water Pollution (2011) $1819,1819-1820$.

${ }^{6}$ United Nations Environment Programme, UNEP Emerging Issues: Environmental Consequences of Ocean Acidification: A Threat to Food Security (2010) 2.

7 Secretariat of the Convention on Biological Diversity, Scientific Synthesis of the Impacts of Ocean Acidification on Marine Biodiversity (2009) 19.

8 Gattuso \& Hansson, above $\mathrm{n} 4$.

9 Buck \& Folger, above n 5, 1819.

${ }^{10}$ United Nations Environment Programme, above n 6.

${ }^{11}$ Intergovernmental Panel on Climate Change, Contribution of Working Group II to the Fourth Assessment Report of the Intergovernmental Panel on Climate Change (2007) 793.

${ }^{12}$ Ibid. 
in warm water than in cold water. ${ }^{13}$ Consequently, marine waters 'near the poles have a much greater capacity for dissolving $\mathrm{CO}_{2}$ than do ocean waters in the tropics. ${ }^{14}$ A recent IPCC Workshop similarly observed that waters of high latitude seas will bear the most impact, and that seasonal aragonite under-saturation in 'surface and shallow subsurface waters over the continental shelves has already been observed in the Chukchi and Bering Seas. ${ }^{15}$

\subsection{The effects on marine ecosystems}

The effects of ocean acidification are numerous and far-reaching. As more $\mathrm{CO}_{2}$ dissolves, calcium carbonate skeletons of many ecologically important groups of marine organisms may actually start to dissolve at or near the ocean surface in some parts of the globe. ${ }^{16}$

Ocean acidification is projected to have huge negative effects on corals and other marine organisms that have a skeleton of calcium carbonate. ${ }^{17}$ Many marine organisms use calcium carbonate to form shells and skeletons, including 'crustose coralline algae, some phytoplankton, warm-and cold-water corals, and a range of pelagic and benthic invertebrates, from small pelagic swimming snails (pteropods) to lobsters. ${ }^{18}$

Ocean acidification poses a significant threat to coral reefs. As the world's oceans become less saturated with respect to calcium carbonate over time, corals are expected to experience reduced survival rates and skeletal growth. ${ }^{19}$ This increases their vulnerability to bio-erosion and storm damage. ${ }^{20}$ Thus habitat quality, diversity, and the loss of coastal protection functions are also reduced. ${ }^{21}$ Ocean acidification will also have serious impacts on the development and survival of cold-water corals. Cold-water coral communities are found throughout the world's oceans at between 200 and 1000 metres depth. ${ }^{22}$ They

\footnotetext{
${ }^{13}$ Buck \& Folger, above n 5, 1820.

14 Ibid.

${ }^{15}$ Intergovernmental Panel on Climate Change, Workshop of the Intergovernmental Panel on Climate Change Workshop on Impacts of Ocean Acidification on Marine Biology and Ecosystems (2011) 137. Aragonite is a mineral consisting of calcium carbonate.

${ }^{16}$ Buck \& Folger, above n 5, 1820.

${ }_{17}$ Secretariat of the Convention on Biological Diversity, above n 12, 30.

${ }^{18}$ Ibid, 32.

${ }^{19}$ Ibid, 37-38.

${ }^{20}$ Ibid, 37-38.

${ }^{21}$ Ibid, 38.

22 Ibid.
} 
provide habitat and support high biodiversity and fisheries. ${ }^{23}$ Being bathed in waters with naturally high levels of $\mathrm{CO}_{2}$, the conditions inhabited by cold-water corals are often less conducive for calcification. ${ }^{24}$ Thus, cold-water coral communities are likely to be the first to experience degradation from increasing ocean acidity. ${ }^{25}$ It is predicted that by the end of this century 70 per cent of known cold-water coral will be affected by corrosive water conditions. ${ }^{26}$

Calcified organisms are major constituents of pelagic ecosystems. They occupy the base of the marine food chain, accounting for the majority of the organic carbon used by organisms in mid and deep-water layers of the oceans, and play a vital role in the interactions of the surface oceans with the atmosphere, such as in the exchange of $\mathrm{CO}_{2}{ }^{, 27}$ Any variations in the functioning of these organisms as a result of ocean acidification could have significant consequences for ecosystem functioning. ${ }^{28}$

Marine fish and marine mammals are also likely to face adverse effects from ocean acidification. In addition to using calcium carbonate for 'strengthening skeletal structures, the use of calcium minerals in gravity sensory organs is widespread among ocean fauna. ${ }^{29}$ When $\mathrm{CO}_{2}$ levels are raised in seawater, 'dissolved $\mathrm{CO}_{2}$ more readily diffuses across animal surfaces'. ${ }^{30}$ Acidification of the body tissues, known as acidosis, can occur in a matter of hours in fish and invertebrates. ${ }^{31}$ This reduces the oxygen carrying capacity of the blood, and is shown to reduce cellular energy and lower respiratory activity. ${ }^{32}$

\section{Ecological impacts}

The impacts that ocean acidification will have on ocean ecosystems, despite having only recently been the focus of study, are manifold. The loss of numerous

\footnotetext{
${ }^{23}$ S C Doney et al, 'Ocean Acidification: The Other $\mathrm{CO}_{2}$ Problem' (2009) 1 Ann R Marine Sci 169, 177.

${ }^{24}$ Secretariat of the Convention on Biological Diversity, above n 12, 39.

${ }^{25}$ Doney et al, above $\mathrm{n} 23$.

${ }^{26}$ Secretariat of the Convention on Biological Diversity, above n 12, 40. Carbonate saturation generally increases with latitude and depth, above n 12,39 .

${ }^{27}$ Ibid, 43.

${ }^{28} \mathrm{Ibid}$.

${ }^{29}$ V J Fabry et al, 'Impacts of Ocean Acidification on Marine Fauna and Ecosystem Processes' (2008) 65 J Marine Sci 414, 420.

${ }^{30}$ Ibid.

${ }^{31}$ Ibid, 421.

${ }^{32}$ Ibid.
} 
calcifying organisms to ocean acidification will 'alter predator-prey relationships' and the effects will be spread throughout ecosystems. ${ }^{33}$ A loss or change in biodiversity could result in significant ecological disruptions. The issue is especially concerning in polar regions, where saturation states of calcium carbonate are naturally low. ${ }^{34}$

As noted earlier, corals will also be particularly vulnerable to the effects of decreasing carbonate saturation states. Consequently, this will negatively affect their 'continued provision of services such as shelter and food for hundreds of associated species, including commercial fish and shellfish.' ${ }^{35}$ Similarly, calcifying pteropods are a key food for carnivorous zooplankton and fish in the polar and sub-polar regions. ${ }^{36}$ Thus, any decline of pteropod densities will influence the predator-prey relationships of many species, including cod, pollock, haddock and mackerel. ${ }^{37}$ This could also result in greater predation on juvenile fish, such as salmon. ${ }^{38}$

Doney and others explain that even small changes in species' reactions will increase over 'successive generations and could drive major reorganisations of planktonic ecosystems. ${ }^{39}$ These issues are further compounded by the fact that ocean acidification is not occurring on its own. This, combined with other stressors such as climate change, invasive species, and overfishing, magnifies the already complex task of assessing the impacts of ocean acidification.

\section{Fisheries, food security and livelihood}

Demand for fish products is expected to grow in the coming decades. The Food and Agriculture Organisation of the United Nations (FAO) notes that considering the expected population increase, an additional ' 27 million tonnes of production will be needed to maintain the present level of per capita consumption in 2030 , 40 The FAO estimates that 32 per cent of the world's fish stocks are overexploited, depleted, or recovering from depletion. ${ }^{41}$ Of even more concern is that 53 per

\footnotetext{
33 Secretariat of the Convention on Biological Diversity, above n 12, 49.

34 Ibid.

35 Ibid, 50.

${ }^{36}$ Doney et al, above n 23, 180.

${ }^{37}$ Secretariat of the Convention on Biological Diversity, above n 12, 51.

38 Ibid.

${ }^{39}$ Doney et al, above n 23, 180.

${ }^{40}$ Food and Agriculture Organisation Fisheries and Aquaculture Department, The State of World Fisheries and Agriculture (2010) 69.

${ }^{41}$ Ibid, 35.
} 
cent have been estimated to be fully exploited, and thus, current catches are at or close to their maximum sustainable productions, with no room for further expansion. ${ }^{42}$ These facts are of grave concern considering that around the world, already declining fish stocks now face new threats posed by ocean acidification.

Fisheries 'hotspots' such as some upwelling regions, coral reefs, estuaries, and sub-polar regions often supplying the main protein source for coastal communities are particularly susceptible to ocean acidification. ${ }^{43}$ Tropical reefs, for example, provide, inter alia, habitat and food for an estimated 25 per cent of known marine fish species. ${ }^{44}$ It is important that ocean $\mathrm{pH}$ remains at a level for coral reefs to persist. Coral reefs provide many ecosystem services that are vital to human society. This includes building materials, reef-based tourism, nursery functions for fisheries, and the welfare associated with the existence of diverse natural ecosystems. ${ }^{45}$

Marine invertebrates increasingly used in aquaculture, such as molluscs and crustaceans, are also prone to the harmful effects of ocean acidification. ${ }^{46}$ For example, ocean acidification is likely to affect the early development of oyster embryos, causing a huge impairment for their survival into adulthood. ${ }^{47}$

The UNEP note that molluscs account for eight per cent of the global marine catch, but are increasingly important in the growing aquaculture industry. ${ }^{48}$ Similarly, crustaceans such as prawns, crabs and lobsters currently make up seven per cent of global seafood consumption through both wild and aquaculture species. ${ }^{49}$ Such invertebrates are often regarded as 'niche luxury foods but also provide significant income for many poor coastal peoples. ${ }^{50}$ As calcification is impaired by increases in ocean acidity, many of these species will be at risk, making them the 'most vulnerable group in the aquaculture sector.' ${ }^{1}$

In sum, any negative impact that increased acidity will have on ocean life will no doubt negatively affect the provision of food, employment and economic activity across the globe. As Turley and Boot concur, the phenomenon has

\footnotetext{
${ }^{42}$ Ibid.

${ }^{43}$ Intergovernmental Panel on Climate Change, above n 15, 33.

${ }^{44}$ United Nations Environment Programme, above n 6, 6.

${ }^{45}$ Secretariat of the Convention on Biological Diversity, above n 12, 53.

${ }^{46}$ United Nations Environment Programme, above n 6, 7.

${ }^{47} \mathrm{H}$ Kurihara, S Kato \& A Ishimatsu, 'Effects of Increased Seawater $\mathrm{pCO}_{2}$ on Early Development of the Oyster Crassostrea Gigas' (2007) 1 Aquatic Bio 91, 95.

${ }^{48}$ United Nations Environment Programme, above n 6, 8.

${ }^{49}$ Ibid.

${ }^{50} \mathrm{Ibid}, 5$.

${ }^{51}$ Ibid.
} 
the potential for widespread and significant effects that will have an impact on humans. ${ }^{52}$

\section{The international law and policy framework}

Just as the effects of ocean acidification are far ranging, so too are the forums that may deal with it. The current international legal machinery in place, that could potentially tackle the problem of ocean acidification, consists of an uncoordinated array of multilateral and regional regimes.

In 2008, 155 scientists from 26 countries, through the Monaco Declaration, called for policymakers to act quickly 'to stabilise atmospheric $\mathrm{CO}_{2}$ at a safe level to avoid not only dangerous climate change but also dangerous ocean acidification. ${ }^{53}$ The responses to ocean acidification by the international community to date have mainly consisted of non-binding calls for cooperation and further research. ${ }^{54}$ For example, the UN General Assembly recently expressed concern as to the effects of ocean acidification and associated negative effects on marine organisms. ${ }^{55}$ It encouraged an increase of national, regional and international efforts to address levels of ocean acidity and the negative impact of such acidity on vulnerable marine ecosystems, particularly coral reefs' ${ }^{56}$

VanderZwaag and Powers note that, inter alia, fragmented legal and institutional arrangements constitute a major challenge that constrains effective protection of the marine environment from land-based activities. ${ }^{57}$ Bodansky similarly observes that 'the lack of coordination between different treaty regimes and international organisations creates the potential for conflicts, gaps, and overlapping, inefficient requirements, or what some have referred to as "treaty congestion". 58 In relation to this, Weiss observes that with such a considerable number of inter-

${ }^{52}$ C Turley \& K Boot, 'The Ocean Acidification Challenges Facing Science and Society' in J Gattuso \& L Hansson (eds), Ocean Acidification (2011) 249, 268.

${ }^{53}$ Second International Symposium on the Ocean in a High- $\mathrm{CO}_{2}$ World Monaco Declaration (ISOPRESS, October 2008).

${ }^{54}$ GA Res 66/231, 5 April 2012, op para 134.

${ }^{55}$ Ibid, Preamble.

${ }^{56}$ Ibid, op para 134.

${ }^{57}$ D L VanderZwaag \& A Powers, "The Protection of the Marine Environment from Land-Based Pollution and Activities: Gauging the Tides of Global and Regional Governance' (2008) 23 Int J Marine \& Coastal Law 423, 437.

${ }^{58}$ D Bodansky, The Art and Craft of International Environmental Law (2010) 267-268. 
national agreements currently in place, there is large potential for inconsistencies in obligations, and the duplication of goals and responsibilities. ${ }^{59}$

Such observations can be highlighted by the problem of ocean acidification. The challenge of arresting the negative effects of the phenomenon exists not only in itself, but also in addressing and navigating the various overlapping international law and policy pertaining to the issue. The climate change regime, various marine pollution regimes, the Convention on Biological Diversity and some regional arrangements could be applied to ocean acidification, albeit at varying levels. These tools are examined below.

\subsection{The climate change regime}

Ocean acidification is a problem concurrent to climate change, sharing the same root cause of anthropogenic $\mathrm{CO}_{2}$ emissions. Reduction of $\mathrm{CO}_{2}$ emissions is the most obvious and effective mitigation strategy for ocean acidification. The consensus amongst scientists is that the smaller the $\mathrm{CO}_{2}$ buildup the less the likelihood of dire impacts. ${ }^{60}$ Thus, the climate regime, comprising the United Nations Framework Convention on Climate Change (UNFCCC) $)^{61}$ and subsequent Kyoto Protocol to the United Nations Framework Convention on Climate Change (Kyoto Protocol), ${ }^{62}$ appears as the most appropriate mechanism to mitigate ocean acidification.

Owing to the relatively recent scientific understanding of the phenomenon, ocean acidification was not comprehensively addressed in the scientific literature when either the UNFCCC or Kyoto Protocol were negotiated. The climate change regime as it currently stands is not immediately applicable to ocean acidification. Therefore, limits or stabilisation targets for atmospheric $\mathrm{CO}_{2}$ based on ocean acidification may differ from those based on surface temperature increases and climate change. ${ }^{63}$ Thus, some provisions are inconsonant with the prevention of ocean acidification. Nonetheless, there are still some provisions in both the UNFCCC and Kyoto Protocol that could arguably be applied to

\footnotetext{
${ }^{59}$ E Brown Weiss, International Environmental Law: Contemporary Issues and the Emergence of a New World Order' (1993) 81 Georgetown LJ 675, 699.

${ }^{60}$ R Eisler, Oceanic Acidification: A Comprehensive Overview (2011) 213.

${ }^{61}$ United Nations Framework Convention on Climate Change, 9 May 1992, 1771 UNTS 107 (UNFCCC).

${ }^{62}$ Kyoto Protocol to the United Nations Framework Convention on Climate Change, 11 December 1997, 2303 UNTS 148 (Kyoto Protocol).

${ }^{63} \mathrm{D}$ EJ Currie \& K Wowk, 'Climate Change and $\mathrm{CO}_{2}$ in the Oceans and Global Oceans Governance' (2009) 4 CCLR 387, 392.
} 
ocean acidification, despite the texts containing no express reference to the phenomenon.

The UNFCCC was created to address the problem of climate change on a legal basis. Article 2 sets out that the ultimate objective of the UNFCCC, and any subsequent legal instruments adopted such as the Kyoto Protocol, is to achieve the 'stabilisation of greenhouse gas concentrations in the atmosphere at a level that would prevent dangerous anthropogenic interference with the climate system. ${ }^{64}$ The definition of climate system includes 'the totality of the atmosphere, hydrosphere, biosphere, geosphere, and their interactions. ${ }^{65}$ As ocean acidification affects the interactions of all these elements of the climate system, and because climate change will have impacts upon the oceans, it seems logical for ocean acidification to be included within the ambit of the definition of 'dangerous anthropogenic interference' in Article 2. In relation to this, Baird, Simons and Stephens note that 'oceans are part of the hydrosphere, marine organisms are part of the biosphere, and atmospheric concentrations of $\mathrm{CO}_{2}$ are inextricably linked to the process of ocean acidification'. ${ }^{66}$

In determining whether 'dangerous anthropogenic interference ${ }^{67}$ has occurred, the parties may draw upon the work of the Subsidiary Body for Scientific and Technical Advice ${ }^{68}$ and the reports of the IPCC. ${ }^{69}$ Thus far, ocean acidification has received some attention in the IPCC Fourth Assessment Report in 2007 and significantly more comprehensive attention in the 'IPCC Workshop on Impacts of Ocean Acidification on Marine Biology and Organisms for the IPCC's Fifth Assessment Report', which is not due however, until 2014. ${ }^{70}$ 'Dangerous anthropogenic interference' has been translated as an increase in global average temperature above two degrees centigrade. ${ }^{71}$ The growing evidence on the perils of ocean acidification may promote recognition of the fact that dangerous anthropogenic interference to the climate system would also constitute a lowering of ocean $\mathrm{pH}$ resulting in increased ocean acidity. Nonetheless, ocean acidification

\footnotetext{
${ }^{64}$ UNFCCC, Art 2.

${ }^{65}$ UNFCCC, Art 1(2).

${ }^{66}$ R Baird, M Simons \& T Stephens, 'Ocean Acidification: A Litmus Test for International Law' (2009) 4 CCLR 459, 463.

${ }^{67}$ UNFCCC, Art 2.

${ }^{68}$ UNFCCC, Art 9.

${ }^{69}$ Baird, Simons \& Stephens, above n 66, 464.

${ }^{70}$ Intergovernmental Panel on Climate Change, The IPCC's Fifth Assessment Report (AR5) Leaflet: Completion Dates (March 2012) <www.ipcc.ch> [accessed 30 March 2013].

${ }^{71}$ C Voigt, 'State Responsibility for Climate Change Damages' (2008) 77 Nordic J Int L 1, 6.
} 
is taking on significance within the climate regime at a slow pace. ${ }^{72}$

In recognition of the practical limitations of the UNFCCC, the Kyoto Protocol was adopted to commit parties by setting internationally binding emission reduction targets. The Kyoto Protocol expands on the UNFCCC process by setting quantified emission limits for each of its member states. ${ }^{73}$ The Kyoto Protocol also contains a provision that may help in preventing ocean acidification requiring that parties protect and enhance 'sinks and reservoirs of greenhouse gases not controlled by the Montreal Protocol. ${ }^{74}$ This could be interpreted as meaning that ocean sinks must be protected from negative impacts, however the word 'enhance' implies that the uptake of $\mathrm{CO}_{2}$ by the oceans is to be encouraged. Baird, Simons and Stephens are of the opinion that this means that parties must act to enhance the 'passive' absorption of anthropogenic $\mathrm{CO}_{2}$ into the oceans. ${ }^{75}$

The climate change regime is still far from the ideal forum to effectively deal with ocean acidification. This conclusion is reinforced by Article 2(1)(iv) of the Kyoto Protocol, which requires states to implement policies and measures such as the 'promotion, development and increased use' of, inter alia, carbon dioxide sequestration technologies. ${ }^{76}$ Thus, the absorption of $\mathrm{CO}_{2}$ by the oceans is regarded as part of the solution to climate change in the climate regime, rather than as a concurrent problem in its own right. While deliberate $\mathrm{CO}_{2}$ sequestration into the oceans may be regarded as a solution for climate change, it may instead worsen ocean acidification. The sustainability of such a provision is questionable. The Secretariat of the Convention on Biological Diversity notes that any geo-engineering or macro-engineering activities that intentionally attempt to enhance $\mathrm{CO}_{2}$ absorption and sequestration in the oceans will exacerbate ocean acidification. ${ }^{77}$ One study also observed that all abundant benthic meiofauna experience high mortality near $\mathrm{CO}_{2}$ disposal sites, shown by higher percentages of dead individuals at the end of the experiment. ${ }^{78}$ In addition,

\footnotetext{
${ }^{72}$ For example, it is mentioned once in the Cancun Agreements in 2010, as part of a footnote, in which it is listed as one of many 'slow onset events' associated with climate change: Conference of Parties, Report of the Conference of the Parties on its sixteenth session, held in Cancun from 29 November to 10 December 2010 FCCC/CP/2010/7/Add.1, 15 March 2011, para 25.

${ }^{73}$ Kyoto Protocol, Art 2.

${ }^{74}$ Kyoto Protocol, Art 2(1)(ii); Montreal Protocol on Substances that Deplete the Ozone Layer, 16 September 1987, 1522 UNTS 3.

${ }^{75}$ Baird, Simons \& Stephens, above n 66, 464.

${ }^{76}$ Kyoto Protocol, Art 2(1)(a)(iv).

${ }^{77}$ Secretariat of the Convention on Biological Diversity, above n 12, 27.

${ }^{78} \mathrm{~J}$ P Barry et al, 'Effects of Direct Ocean $\mathrm{CO}_{2}$ Injection on Deep-Sea Meiofauna' (2004) $60 \mathrm{~J}$
} 
opportunities for generating profitable 'carbon offsets' by using as yet unproven ocean fertilisation technologies in an effort to generate algal blooms that might fix more $\mathrm{CO}_{2}$ in the ocean are being explored by entrepreneurs. ${ }^{79}$ Such measures are inconsistent with Article 3(3) of the UNFCCC, which requires that parties take precautionary actions to prevent or minimise climate change causes. ${ }^{80}$

The solution to climate change envisioned by the Kyoto Protocol is that states reduce 'aggregate anthropogenic carbon dioxide equivalent emissions' of greenhouse gases below specified levels, and requiring industrialised states to reduce these emissions to 'at least 5 per cent below 1990 levels. ${ }^{81}$ It accordingly assigns to each industrialised country an amount of allowable greenhouse gas emissions. ${ }^{82}$ Such provisions demonstrate an atmospheric focus and are obviously inadequate in preventing ocean acidification. This is because carbon dioxide is not regulated specifically. The implication of aggregating all six of the main greenhouse gases ${ }^{83}$ when setting such allowances is that parties to the Kyoto Protocol are still able to increase their $\mathrm{CO}_{2}$ emissions, so long as they decrease their emissions of other greenhouse gases, such as methane and nitrous oxide. ${ }^{84}$ This demonstrates the fact that ocean acidification is not yet a serious concern of the climate change regime.

The threats associated with ocean acidification, while slowly gaining recognition, have not been fully appreciated by the climate regime. The atmospheric focus of the climate regime makes it limited in dealing with ocean acidification. Currie and Wowk note that consideration 'needs to be given to the necessity of regulating $\mathrm{CO}_{2}$ emissions directly, separate from their radiative forcing effects and their combination with other greenhouse gases' ${ }^{85}$

Even if ocean acidification was to be expressly recognised within the climate change regime, the benefits of such recognition would still be limited by the regime's general disadvantages. For example, the emissions control system under the Kyoto Protocol does not cover fast-growing countries such as China,

\footnotetext{
Oceanography 759, 764.

79 D Freestone, 'Problems of High Seas Governance' in D Vidas \& P J Schei (eds), World Ocean in Globalisation: Climate Change, Sustainable Fisheries, Biodiversity, Shipping, Regional Issues (2011) 99, 101-102.

${ }^{80}$ UNFCCC, Art 3(3).

${ }^{81}$ Kyoto Protocol, Art 3(1).

${ }^{82}$ Kyoto Protocol, Art 3(7).

${ }^{83}$ Ibid, Annex A, this includes carbon dioxide, methane, nitrous oxide, hydro fluorocarbons, perfluorocarbons, sulphur hexafluoride.

${ }^{84}$ Baird, Simons \& Stephens, above n 66, 464.

${ }^{85}$ Currie \& Wowk, above n 63, 392.
} 
India and Brazil. ${ }^{86}$ Moreover, Burns observes that even if the Kyoto Protocol were fully adhered to by all industrialised nations as originally drafted, which has not 'proven to be the case to date, it would only constitute a very modest down payment on what ultimately must be done to stabilise atmospheric concentrations of greenhouse emissions. ${ }^{87}$ Babiker and others note that keeping within the Kyoto Protocol emission limits, even with the participation of the US, would only reduce temperatures by some $0.5^{\circ} \mathrm{C}$ by 2100 and both rising global emissions and atmospheric concentrations will continue. ${ }^{88}$

Overall, the response under this regime, to date, is inadequate. This simply owes to the fact that the climate regime, in its current state, has not been tailored to effectively ameliorate the negative effects of ocean acidification.

\subsection{Marine pollution regimes}

\subsubsection{The United Nations Convention on the Law of the Sea}

Forming the basis of environmental protection in marine areas within and beyond national jurisdiction is the United Nations Convention on the Law of the Sea (UNCLOS). ${ }^{89}$ The treaty outlines guidelines, rights and responsibilities relating to utilisation of the oceans including, inter alia, boundary delineation, ${ }^{90}$ the rights of each coastal state jurisdiction over fishery resources within an exclusive economic zone (EEZ), ${ }^{91}$ and dispute settlement. ${ }^{92}$ While the issue of ocean acidification affects waters both inside and outside national jurisdiction, it is highly questionable whether it falls within the remit of UNCLOS.

What may constitute pollution of the marine environment is detailed under Article 1 of UNCLOS as follows:

\footnotetext{
${ }^{86}$ This is because of issues over the fact that unfair burdens would be placed upon developing states. Additionally, industrialised countries are primarily responsible for the buildup of greenhouse gases, and have greater financial and technological capacity to address the problem, see: K A Baumert, 'Participation of Developing Countries in the International Climate Change Regime: Lessons for the Future' (2006) 38 Georgetown Washington Int L R 365, 366.

${ }^{87}$ W C G Burns, 'Potential Causes of Action for Climate Change Damages in International Fora: The Law of the Sea Convention' (2006) 2 McGill Int J Sustainable Development L \& Policy 27, 30-31.

${ }^{88}$ M H Babiker et al, 'The Evolution of a Climate Regime: Kyoto to Marrakech and Beyond' (2002) 5 Env Sci \& Policy 195, 202.

${ }^{89}$ United Nations Convention on the Law of the Sea, 10 December 1982, 1833 UNTS 3 (UNCLOS). To date, 165 nations are parties to UNCLOS.

${ }^{90}$ Ibid, Part II.

${ }^{91}$ Ibid, Part V.

${ }^{92}$ Ibid, Part XV.
} 
[T] he introduction by man, directly or indirectly, of substances or energy into the marine environment, including estuaries, which results or is likely to result in such deleterious effects of harm to living resources and marine life, hazards to human health, hindrance to marine activities, including fishing and other legitimate uses of the sea, impairment of quality for use of sea water and reduction of amenities. $^{93}$

Doelle notes that the plain wording of this definition suggests that its ultimate objective is to capture a wide array of potential threats to the marine environment. ${ }^{94}$ It has been noted that UNCLOS is not a contract that was 'frozen in the time it was negotiated', as such an approach would 'relegate many international treaties to irrelevance soon after they are negotiated. ${ }^{95}$ Indeed, UNCLOS needs to be interpreted in a dynamic way in order for international treaties to be utilised over time. ${ }^{96}$ Thus, despite the fact ocean acidification was not recognised during the time UNCLOS was negotiated, it would be illogical to exclude anthropogenic $\mathrm{CO}_{2}$ emissions from the ambit of this definition-especially given that this is the direct cause of ocean acidification and because of the harmful effects this may have on marine ecosystems.

Part XII of UNCLOS deals with protection and preservation of the marine environment, and establishes a 'general obligation' on states to protect and preserve the marine environment. ${ }^{97}$ On evaluating the provisions of Part XII, McConnell and Gold explain that they are not merely a restatement of existing conventional law or practice, but are of constitutional nature, and provide the first 'comprehensive statement of international law on the issue. ${ }^{98}$

Article 194(1) of UNCLOS specifies obligations by enshrining a duty upon states to 'prevent, reduce and control pollution of the marine environment from any source' (emphasis added). ${ }^{99} \mathrm{CO}_{2}$ emissions, being a source of pollution, would accordingly fit within the purview of this obligation. However, as observed by Kunich, this article is weakened by the proviso that states shall make these

\footnotetext{
${ }^{93}$ UNCLOS, Art 1(1)(4).

${ }^{94}$ M Doelle, 'Climate Change and the Use of the Dispute Settlement Regime of the Law of the Sea Convention' (2006) 37 J Ocean Development \& Int L 319, 322.

95 Ibid.

96 Ibid.

${ }^{97}$ UNCLOS, Art 192.

${ }^{98}$ M L McConnell \& E Gold, 'The Modern Law of the Sea: Framework for the Protection and Preservation of the Marine Environment?' (1991) 23 Case Western Reserve J Int Law 83, 84.

${ }^{99}$ UNCLOS, Art 194(1).
} 
efforts using the 'best practical means at their disposal' and 'in accordance with their abilities.' ${ }^{\prime}$ The uncertainty of this proviso undermines the ability of the international community to urge for compliance with the UNCLOS provisions. Under Article 194, UNCLOS further specifies an obligation to prevent pollution from spreading to areas outside of a state's jurisdiction of control, ${ }^{101}$ so as to not cause damage by pollution to other states and their environment; ${ }^{102}$ and an explicit obligation to protect and preserve rare or fragile ecosystems, and the habitat of species at risk. ${ }^{103}$ The latter requirement holds particular relevance, as coral reef ecosystems are particularly vulnerable to ocean acidification. The likely effect of such obligations under Article 194 will be that states will use their discretion in determining what are the best means to achieve such obligations at their disposal. ${ }^{104}$ While Article 207(4) goes on to provide that states 'endeavour to establish global and regional rules, standards and recommended practices' for the control of land-based pollution. ${ }^{105}$ Birnie, Boyle and Redgewell observe the hortatory nature of this wording, particularly the use of the word 'endeavour.' ${ }^{106}$ This suggests that the level of commitment by states is voluntary and may vary. Article 207(4) also allows states to take into account 'characteristic regional features, the economic capacity of developing states and their need for economic development. ${ }^{\prime}$ They further note that such phraseology demonstrates that states wish to commit themselves to weak international regulation, greater liberty for giving preference to other national priorities, and reliance on regional cooperation as the main level at which international action should occur. ${ }^{108}$ Overall, Article 207 as is, does not require states to implement strong or effective measures. $^{109}$

Of further applicability to ocean acidification, UNCLOS covers atmospheric pollution, as it imposes a duty on states to 'adopt laws and regulations to prevent, reduce and control pollution of the marine environment from or through the atmosphere.'110 Doelle accepts that this obligates states to 'prevent or control

\footnotetext{
${ }^{100}$ Ibid. J C Kunich, Killing Our Oceans Dealing With the Mass Extinction of Marine Life (2006) 56.

${ }^{101}$ UNCLOS, Art 194(2).

${ }^{102}$ UNCLOS, Art 194(2).

${ }^{103}$ UNCLOS, Art 194(5).

${ }^{104} \mathrm{R}$ Zajacek, 'Measures to Protect the Marine Environment' (1996) 3 JCULR 64, 75.

${ }^{105}$ UNCLOS, Art 207(4).

${ }^{106} \mathrm{P}$ Birnie, A Boyle \& C Redgwell, International Law and the Environment (2009) 454.

${ }^{107}$ UNCLOS, Art 207(4).

${ }^{108}$ Birnie, Boyle \& Redgwell, above n 106, 454.

${ }^{109}$ Ibid.

${ }^{110}$ UNCLOS, Art 212.
} 
pollution from or through any air space over which a state has jurisdiction.'111 This clause seems to be precisely relevant to the issue of ocean acidification and places an obligation on the shoulders of states to prevent, reduce and control acidification resulting from $\mathrm{CO}_{2}$ emissions. In achieving this, states are also required to take into account internationally agreed rules, standards and recommended practices and procedures. ${ }^{112}$ The parties are required to act through competent organisations or diplomatic conferences to create measures to 'prevent, reduce, and control such pollution.'.13 Given that the UNFCCC is an international body that deals with reducing carbon emissions, and contributing to the protection and preservation of the marine environment by implication, it appears as the most 'competent organisation' in the context of ocean acidification. However the relevance of the UNFCCC in relation to this issue remains uncertain, as noted earlier, the UNFCCC does not specifically acknowledge the potential impacts of ocean acidification on marine ecosystems. Indeed, any gaps left by UNCLOS in relation to ocean acidification, cannot be filled by reference to the climate change regime in its current state.

Based on first impressions, Part XII of UNCLOS appears as a potentially useful avenue for addressing ocean acidification. Closer analysis, however, casts doubt on its efficacy. The problem, as Ong points out, is that UNCLOS in itself does not contain concrete marine pollution standards, nor does it purport to substitute for special agreements. ${ }^{114}$ Its drawbacks are that it is weak in indicating precisely what constitutes a violation, and what consequences flow from this as far as liability is concerned. ${ }^{115}$ There are questions that remain unaddressed by this governing international legal framework for addressing marine environmental protection issues. ${ }^{116}$ These questions make it uncertain whether marine protection afforded by UNCLOS would be sufficient in curbing the negative effects of ocean acidification. In particular: ${ }^{117}$

1. What threshold of harm needs to be established for 'environmental' damage to be proven?

\footnotetext{
${ }^{111}$ Doelle, above n 94, 323.

${ }^{112}$ UNCLOS, Art 212(1).

${ }^{113}$ UNCLOS, Art 212(3).

${ }^{114}$ D M Ong, 'The 1982 UN Convention on the Law of the Sea and Marine Environmental Protection' in Fitzmaurice, Ong \& Merkouris (eds), above n 1, 567, 571.

115 Ibid.

${ }^{116}$ Ibid, 573.

${ }^{117}$ Ibid.
} 
2. Assuming that responsibility for such harm can be assigned, whether it is to be assigned to a private or public entity (or both); who or what body can in turn claim on behalf of the 'environment'? and,

3. What kind of legal remedies should be made available to address 'environmental' harm?

This leads to uncertainty as to whether a claim could be made against a state that fails to mitigate ocean acidification, and whether its failure to do so would violate its obligations under UNCLOS. Some writers have already explored the possibility of bringing climate change actions under the dispute resolution procedures established within Part XV of UNCLOS, against parties to the Convention. ${ }^{118}$ In situations where disputes connected to the interpretation of UNCLOS arise and cannot be resolved through an exchange of view or conciliation, ${ }^{119}$ Part XV of UNCLOS provides four options for dispute settlement: the International Tribunal for the Law of the Sea, ${ }^{120}$ the International Court of Justice, an arbitral panel or a special arbitral panel. ${ }^{121}$ Resorting to methods outside the climate regime may become necessary. As Burns observes that as the presence of climate change is more apparent now than a decade ago, the prospects for 'adequate responses within the UNFCCC framework appear increasingly remote.' ${ }^{122}$ Thus, recourse to the Part XV of UNCLOS could be a useful alternative with regards to ocean acidification, in motivating the major carbon emitting states to act to avoid its harmful effects.

One notable issue in bringing a claim would be attributing causation of harm to a specific state. Applied to the issue of ocean acidification, a claim could potentially be brought against a state with both a high financial ability to address the problem and high historical per capita contribution to carbon concentrations in the atmosphere above accepted levels. Doelle suggests other decisive factors include ratification of the Kyoto Protocol, per capita emissions compared to other states, and whether the state is a party to UNCLOS and the UNFCCC. ${ }^{123}$ Smith and Shearman observe that the Kyoto Protocol is generally considered by

\footnotetext{
${ }^{118}$ See generally Doelle, above n 94; Burns, above n 87.

${ }^{119}$ UNCLOS, Art 279-285.

${ }^{120} \mathrm{Ibid}$, Annex VI.

${ }^{121}$ Ibid, Art 287(1).

${ }^{122}$ W C G Burns, 'Potential Causes of Action for Climate Change Impacts under the United Nations Fish Stocks Agreement' in W C G Burns \& H M Osofsky (eds), Adjudicating Climate Change (2009) 314, 332-333.

${ }^{123}$ Doelle, above n 94, 325.
} 
the international community as the appropriate response to global warming. ${ }^{124}$ Therefore, nations that meet their greenhouse gas emission targets under the Protocol arguably have a strong defense to climate change suits based on the fact that they are doing all the international community requires of them. ${ }^{125}$ By comparison, suggesting that the Kyoto Protocol would have bearing on a determination of whether a state has taken sufficient action to mitigate ocean acidification would not be an appropriate benchmark to hold states to in regards to ocean acidification. This is simply because the phenomenon is not currently acknowledged under the Kyoto Protocol, thus, there is currently no express standard under international law to hold states to. Under the climate regime, carbon emission reduction goals to specifically mitigate ocean acidification, or even prevent harm to marine environment, have not yet been espoused.

As coral reefs are likely to experience the negative effects of ocean acidification, a claim could hypothetically be made by island states with coral reefs, who have a high vulnerability to ocean acidification, and whose livelihood is dependent on the food, tourism, ecosystem services, and barrier protection provided by coral reefs. Likewise, as polar regions are likely to be the first to experience the negative effects of ocean acidification, citizens of arctic states whose livelihood is dependent on the health of their marine environment could also be considered. A party to UNCLOS pursuing an action based on ocean acidification would face considerable obstacles, however, such as establishing causation. Indeed, establishing a causal link between ocean acidification and damages to marine resources may prove difficult. Burns notes the example of coral reefs, which are exposed to other threats that may also contribute to their degradation, such as terrestrial runoff, disease, and other sources of pollution. ${ }^{126}$ Establishing links of this regard could require extensive and expensive research that could go beyond the capacity of smaller and more vulnerable states. ${ }^{127}$ Determining the connection between a party's individual carbon emissions and alleged damages may likewise prove difficult. As mentioned earlier, ocean acidification has only recently gained awareness and was not addressed in the scientific literature during the negotiations of the climate change regime. There will always be legal difficulties in attributing blame for activities that were not envisaged as causing harm at the point carried out. However, in deciding whether a party did not take adequate action to mit-

\footnotetext{
${ }^{124} \mathrm{~J}$ Smith \& D Shearman, Climate Change Litigation: Analysing the Law, Scientific Evidence and Impacts on the Environment, Health and Property (2006) 19.

${ }^{125} \mathrm{Ibid}$.

${ }^{126}$ Burns, above n 87, 49.

${ }^{127}$ Ibid, 50.
} 
igate its contribution to ocean acidification, considerations could, as suggested by Doelle in relation to climate change, include "how much higher the contribution of that country is relative to other countries, how relevant is the capacity to reduce emissions, and the effect of the historical contribution to the problem.' ${ }^{128}$

Another limitation of using UNCLOS to address ocean acidification is that some states have not ratified it. For example, it has not been ratified by the United States, a nation with high per capita greenhouse gas emissions. Thus, the United States is not at risk of being pursued under the UNCLOS tribunal. ${ }^{129}$ Furthermore, even if as commentators have supported, the provisions of UNCLOS form part of customary international law, ${ }^{130}$ the United States has withdrawn its acceptance of the compulsory jurisdiction of the International Court of Justice. As such, the United States could not be pursued in that forum either for breaches of such law. ${ }^{131}$ Thus, jurisdiction may be an additional hurdle.

Moreover, there is the issue of what reparation would be available for environmental harm caused by ocean acidification. It is doubtful whether reparation in the form of monetary compensation would be the most appropriate solution to ocean acidification. There is also restitutio in integrum-a commitment to restore a damaged environment to its former state. ${ }^{132}$ It is uncertain however, whether this would be a scientifically achievable option with regards to ocean acidification. A small degree of consolation may be offered by the fact that if regimes such as the climate change regime cannot satisfy in providing adequate prevention from the negative effects arising from ocean acidification, there still exists the additional option of recourse to Part XV for states to pursue. Nonetheless, any remedy provided under the dispute resolution procedures under Part XV of UNCLOS is likely to provide a 'reactive' rather than 'preventative' measure to any potential environmental harm caused by ocean acidification.

\subsubsection{The dumping regime}

While the natural absorption of $\mathrm{CO}_{2}$ from the atmosphere may potentially fall within the regulatory domain of the climate change regime and UNCLOS, the

\footnotetext{
${ }^{128}$ Doelle, above $n 94,332$.

${ }^{129} \mathrm{Ibid}$

${ }^{130} \mathrm{~J}$ M Van Dyke, 'Giving Teeth to the Environmental Obligations in the LOS Convention' in L G Oude Elferink \& D R Rothwell (eds), Ocean Management in the 21st Century: Institutional Frameworks and Responses (2004) 167.

${ }^{131}$ Burns, above n 87, 45.

${ }^{132}$ Ong, above n 114, 573.
} 
deliberate disposal of carbon wastes in the sea is addressed through the dumping regime. This includes the 1972 Convention on the Prevention of Marine Pollution by Dumping of Wastes and other Matter (1972 London Convention) ${ }^{133}$ and the 1996 Protocol to the London Convention (1996 London Protocol). ${ }^{134}$ The 1996 London Protocol was negotiated to replace the 1972 London Convention. While it has entered into force, the two regimes operate in tandem as it currently has low participation. $^{135}$

Amendments to the 1996 London Protocol were adopted in November 2006 at the First Meeting of Contracting Parties, and were created to permit and regulate the sequestration of $\mathrm{CO}_{2}$ in sub-seabed geological formations. ${ }^{136}$ These amendments were supplemented by 'Specific Guidelines for Assessment of Carbon Dioxide Streams for Disposal into Sub-Seabed Geological Formations.' ${ }^{137}$ The guidelines are comprehensive and require that proposals for sub-seabed sequestration undergo thorough assessment and alternative land-based disposal be appropriately considered. ${ }^{138}$ One problem with this, as Warner notes, is that while these Guidelines help to prevent the risks of this form of waste disposal at sea, they only apply to the inadequate number of state parties to the 1996 London Protocol, their flag vessels, and activities under their jurisdiction and control. ${ }^{139}$ Moreover, the dumping regime can address ocean acidification 'only in so far as it is caused by the dumping of $\mathrm{CO}_{2}$ wastes at sea.' ${ }^{140}$ Consequently, Simons and Stephens observe that this regime 'can only regulate one relatively small potential driver of ocean acidification.'.141

${ }^{133}$ Convention on the Prevention of Marine Pollution by Dumping of Wastes and Other Matter, 29 December 1972, 1046 UNTS 120 (1972 London Convention).

${ }^{134}$ Protocol to the Convention on the Prevention of Marine Pollution by Dumping of Wastes and Other Matter, 7 November 1996, 2006 ATS 11 (1996 London Protocol).

${ }^{135} \mathrm{R}$ Warner, 'Preserving a Balanced Ocean: Regulating Climate Change Mitigation Activities in Marine Areas Beyond National Jurisdiction' (2007) 14 Aus Int LJ 99, 111.

${ }^{136} \mathrm{IMO}$, 'New International Rules to Allow Storage of $\mathrm{CO}_{2}$ under the Seabed' (Press Release, 9 February 2007); IMO, Resolution on the Amendment to Include $\mathrm{CO}_{2}$ Sequestration in Sub-Seabed Geological Formations in Annex 1 to the London Protocol, IMO Res LP.1(1), 2 November 2006.

${ }^{137}$ IMO, Specific Guidelines for Assessment of Carbon Dioxide Streams for Disposal into Sub-Seabed Geological Formations, IMO Doc. LC 29/4, November 2007.

${ }^{138} \mathrm{Ibid}$, paras 3-4.

${ }^{139}$ Warner, above n 135, 114. To date 41 nations are parties to the 1996 London Protocol, International Maritime Organisation, Status of Multilateral Conventions and Instruments in Respect of Which the International Maritime Organisation or its Secretary-General Performs Depository or Other Functions (2012) 500.

${ }^{140} \mathrm{M}$ Simons \& T Stephens, 'Ocean Acidification: Addressing the Other $\mathrm{CO}_{2}$ Problem' (2009) 12 Asia Pacific J Env L 1, 11.

${ }^{141}$ Ibid, 10. 


\subsubsection{The 1995 Global Programme of Action for the Protection of the Marine Environment from Land-Based Activities}

Ocean acidification largely results from human activity, particularly fossil fuel burning that occurs on land. It would therefore seem reasonable to consider the main international initiative that addresses pollution from land-based activities: the Global Programme of Action for the Protection of the Marine Environment from Land-based Activities (GPA), adopted by 108 states and the European Commission in $1995 .{ }^{142}$ The GPA is not legally binding. It consists of various non-binding (or 'soft') global obligations for land-based marine pollution and activities. It has been created as a 'source of conceptual and practical guidance' to be utilised by national and regional authorities in establishing measures to 'prevent, reduce, control and eliminate marine degradation from land-based activities.' ${ }^{\prime 23}$ The reason why a binding global treaty was not adopted is that it was believed that the issues were of a regional rather than global nature and that regional differences made a common international approach difficult. ${ }^{144}$ Many countries saw stronger international regulation as an intrusion in national matters. ${ }^{145}$ Thus, the GPA was designed more as a tool of assistance.

Under the GPA, states are urged to establish national programmes of action to prevent degradation of the marine environment from land-based pollution. ${ }^{146}$ The GPA would presumably have a responsibility in facilitating national programmes of action with regard to circumventing ocean acidification; owing to the fact ocean acidification is a type of marine degradation caused by the emission of anthropogenic $\mathrm{CO}_{2}$-a primarily land-based activity. Chapter $\mathrm{V}$ of the GPA puts forward that states set specific targets in relation to nine major sources of concern, including 'sewage, persistent organic pollutants, radioactive substances, heavy metals, oils, nutrients, sediment mobilization, litter and physical alterations. ${ }^{147}$ Nonetheless, carbon emissions currently fall outside of these categories of contaminants acknowledged by the GPA.

VanderZwaag and Powers have similarly observed that the role of the GPA in dealing with 'climate change impacts on coastal and freshwater ecosystems

\footnotetext{
${ }^{142}$ United Nations Environment Programme, Global Programme of Action for the Protection of the Marine Environment from Land-based Activities, UNEP(OCA)/LBA/IG.2/7, 5 December 1995 (GPA).

${ }^{143} \mathrm{Ibid}$, para 14.

${ }^{144}$ Birnie, Boyle \& Redgwell, above n 106, 465.

${ }^{145}$ Ibid.

${ }^{146} \mathrm{GPA}$, para 19 .

${ }^{147} \mathrm{Ibid}$, paras 21(b)-21(c).
} 
remains uncertain' ${ }^{148}$ The UNFCCC is noted under the GPA as a global convention that elaborates upon 'the duty of States to preserve and protect the marine environment. ${ }^{149}$ Atmospheric deposition from transportation, power plants and industrial facilities are also mentioned as a source of degradation, ${ }^{150}$ however the GPA does not elucidate what the constituents of such atmospheric deposition are. The GPA is essentially silent on both climate change and ocean acidification. The Beijing Declaration on Furthering the Implementation of the Global Programme of Action for the Protection of the Marine Environment from Land-based Activities (Beijing Declaration) ${ }^{151}$ in 2006 did, nonetheless, acknowledge the vulnerabilities of coastal and island communities to the 'effects on the marine environment of ocean acidification resulting from land-based activities. ${ }^{152}$ However, despite acknowledgement of this, the GPA still has not been revised to have a major role in the issue of ocean acidification. Moreover, the mention of the UNFCCC as a convention that includes principles and approaches that elaborate on the prevention of the degradation of the marine environment ${ }^{153}$ suggests that the GPA is leaving the regulation of greenhouse gas emissions to be addressed in the forum of the climate change regime.

Regardless of the fact that carbon emissions fall outside of the nine source categories of land-based marine pollutants, and thus the current major purview of the GPA, the regime is fraught with its own limitations. In particular, the 'soft law' nature of the document, ${ }^{154}$ that consequently allows states to retain complete control over the degree of commitment. Moreover, the GPA lacks detailed and enforceable pollution standards, ${ }^{155}$ and since its inception, it has struggled to mobilise financial resources to help implement national and regional programmes. ${ }^{156}$ Thus, the GPA may not be the most appropriate avenue in which to address the serious impacts of ocean acidification. Because ocean acidification poses a significant issue to global oceans, and as there is already reluctance by

\footnotetext{
${ }^{148}$ VanderZwaag \& Powers, above n 57, at 439.

${ }^{149}$ GPA, para 7.

${ }^{150}$ Ibid, para 21(d)(iii).

${ }^{151}$ United Nations Environment Programme, Report of the Second Session of the Intergovernmental Review Meeting on the Implementation of the Global Programme of Action for the Protection of the Marine Environment from Land-based Activities, UNEP/GPA/IGR.2/7, 23 October 2006, Annex V (Beijing Declaration).

${ }^{152}$ Ibid, Preamble.

${ }^{153}$ United Nations Environment Programme, above n 142, para 7.

${ }^{154}$ VanderZwaag \& Powers, above n 57, 441.

${ }^{155}$ Ibid.

${ }^{156}$ Ibid, 439-440.
} 
states to reduce carbon emissions, it is thus submitted that hard law must form the basis of any solution.

\subsection{The Convention on Biological Diversity}

A traversal of the main legal instruments addressing the issue of ocean acidification would not be complete without mention of the United Nations Convention on Biological Diversity $(C B D) .{ }^{157}$ Indeed, a wide range of marine organisms and ecosystems are vulnerable to the phenomenon. Oceans cover the majority of the earth's surface and consequently, this phenomenon poses a significant threat to marine biodiversity.

The CBD is the main international agreement that governs biodiversity issues. The aims of the CBD include conserving biological diversity, sustainable use, and fair and equitable sharing of the benefits arising from the use of genetic resources. ${ }^{158}$ The CBD expressly includes 'marine and other aquatic ecosystems and the ecological complexes of which they are part' in its definition of biological diversity to be conserved under the Convention. ${ }^{159}$ The CBD also contains precautionary undertones, for example, the Preamble provides:

[T] hat where there is a threat of significant reduction or loss of biological diversity, lack of full scientific certainty should not be used as a reason for postponing measures to avoid or minimize such a threat. 160

A lack of full scientific certainty cannot be used as a reason for failing to take suitable action to safeguard biodiversity from the negative effects of ocean acidification. The CBD also directs each party to identify processes and types of activities that have, or are likely to have, major adverse consequences on the conservation and sustainable use of biological diversity, and to monitor their effects. ${ }^{161}$ Article 14 also states that notification, consultation, and the exchange of information on activities under their jurisdiction or control 'which are likely to significantly affect adversely the biological diversity of other states

\footnotetext{
${ }^{157}$ Convention on Biological Diversity, 5 June 1992, 1760 UNTS 79 (CBD).

${ }^{158} \mathrm{CBD}$, Art 1 .

${ }^{159} \mathrm{Ibid}$, Art 2.

${ }^{160} \mathrm{Ibid}$, Preamble.

${ }^{161}$ Ibid, Art 7.
} 
or areas beyond the limits of national jurisdiction' are encouraged through the establishment of bilateral, regional and multilateral agreements. ${ }^{162}$

There are an impressive 193 parties to the CBD. ${ }^{163}$ Many of the major carbon emitting participants such as China and the European Union are parties to the CBD. ${ }^{164}$ This is relevant as, for example, while developing states in transition who have high carbon emissions may evade the emissions control system set out under the climate regime, they still have duties to protect and conserve the marine environment, and thus to avoid ocean acidification under the CBD. This demonstrates that while the myriad regimes relating to ocean acidification may create inefficiencies, they can, on the other hand, supplement and reinforce one another.

Concerns were raised about the impacts of ocean acidification at the Ninth Meeting of the Conference of Parties (COP) to the CBD in 2008, leading to a decision to be adopted regarding the phenomenon. ${ }^{165}$ This included a request of the Executive Secretary to collect and combine available scientific information on ocean acidification and its consequences on marine biological diversity and habitats. ${ }^{166}$ In direct response to this request a Scientific Synthesis of the Impacts of Ocean Acidification on Marine Biodiversity was prepared. ${ }^{167}$ This demonstrates that ocean acidification is indeed gaining deserved attention under the CBD.

Another important decision in relation to ocean acidification occurred at the Tenth Meeting of the Conference of Parties to the CBD in 2010. It was requested that the Executive Secretary collaborate with the Intergovernmental Oceanographic Commission of the United Nations Educational, Scientific and Cultural Organization (UNESCO), the Food and Agriculture Organisation, the Secretariat of the UNFCCC, the World Conservation Monitoring Centre of the United Nations Environment Programme, the International Coral Reef Initiative, Ramsar Convention, the Arctic Council, and other relevant organisations and

\footnotetext{
${ }^{162} \mathrm{Ibid}$, Art 14(c).

${ }^{163}$ UN Secretariat, 'Chapter XXVII:8 Convention on Biological Diversity', Multilateral Treaties Deposited with the Secretary-General, United Nations Treaty Collection <http://un.treaties.org> [accessed 30 March 2013].

${ }^{164}$ The United States is signatory to both the Kyoto Protocol and the CBD but is not a party to either agreement.

${ }^{165}$ Conference of Parties, Decisions Adopted by the Conference of the Parties to the Convention on Biological Diversity at its Ninth Meeting: IX/20 Marine and Coastal Biodiversity, UNEP/CBD/COP/9/29, May 2008, 114, para 4.

${ }^{166} \mathrm{Ibid}$.

${ }^{167}$ Secretariat of the Convention on Biological Diversity, above $\mathrm{n} 12$.
} 
scientific groups. ${ }^{168}$ This was in order to develop a series of joint expert review procedures to monitor and assess the effects of ocean acidification on marine and coastal biological diversity. ${ }^{169}$ This would accordingly highlight the importance of the issue to parties, other governments and organisations. ${ }^{170}$ This represents a positive step in achieving integration and coordination with regards to the many existing regimes that are related to the matter.

Parties were also 'invited' in accordance with internal circumstances and priorities, to consider the following guidance on conserving and restoring biodiversity and ecosystem services while contributing to climate-change mitigation:

Identify, monitor and address the impacts of climate change and ocean acidification on biodiversity and ecosystem services, and assess the future risks for biodiversity and the provision of ecosystem services using the latest available vulnerability and impact assessment frameworks and guidelines. ${ }^{171}$

This work by the CBD parties is laudable. However, it is limited by the fact that any decisions made regarding the mitigation of ocean acidification are ultimately reliant on voluntary compliance by states. The CBD cannot regulate the impacts of ocean acidification by any enforceable means, as the CBD does not grant the power to legally bind the contracting parties to the COP. ${ }^{172}$ Likewise, Simons and Stephens note that it is doubtful whether any of the provisions of the CBD 'could be used to impose a clearly-defined obligation on states parties to limit their $\mathrm{CO}_{2}$ emissions by reference to the impact of these emissions on acidity levels in the oceans.'.73

In summary, there are numerous provisions in widely-accepted regimes that deal with protecting the marine environment. The regime that appears to bear a strong level of applicability to curbing the negative consequences of ocean acidification is the climate change regime. Although it does not expressly

\footnotetext{
${ }^{168}$ Conference of Parties, Decisions Adopted by the Conference of the Parties to the Convention on Biological Diversity at its Tenth Meeting: X/29 Marine and Coastal Biodiversity, UNEP/CBD/COP/DEC/X/29, October 2010, 229, para 66.

${ }^{169} \mathrm{Ibid}$

${ }^{170}$ Ibid.

${ }^{171}$ Conference of Parties, Decisions Adopted by the Conference of the Parties to the Convention on Biological Diversity at its Tenth Meeting: X/33 Biodiversity and Climate Change UNEP/CBD/COP/DEC/X/33, October 2010, 271, para 8(a).

${ }^{172}$ A Proelss \& M Krivickaite, 'Marine Biodiversity and Climate Change' (2009) 4 CCLR 437, 440.

${ }^{173}$ Simons \& Stephens, above n 140, 17.
} 
refer to ocean acidification, any reductions in $\mathrm{CO}_{2}$ instigated by the climate regime, as currently worded, will inadvertently help to reduce ocean acidity. Nonetheless, ocean acidification is not explicitly recognised under this regime, and no stabilisation targets to mitigate the problem have been set.

While it is clear that the provisions set out under the various regimes may be employed to deal with ocean acidification, such provisions are insufficient without clear recognition of the problem. Existing regimes may tangentially, rather than fully, address ocean acidification, leaving the issue in a precarious position.

\section{Future directions}

While the various regimes examined do provide some, albeit uncertain, degree of protection from the negative effects of ocean acidification, there is much more that needs to be achieved in terms of developing a coherent solution to the problem. Lamirande suggests that an international treaty that specifically addresses ocean acidification is needed, ${ }^{174}$ as current international agreements do not contain strict enough requirements for achieving necessary results. ${ }^{175}$ The author also argues that unlike the climate change regime, a treaty on ocean acidification would clarify 'the expectations of each country in limiting and reducing its amount of [greenhouse gas] emissions overall.'. ${ }^{176}$

While the adoption of a new international treaty appears as an obvious and appropriate solution, it could nevertheless add further complexity, as there a variety of regimes that some commentators have described as 'more or less fixtures in international law' ${ }^{177}$ already exist. Accordingly, there is no 'clean slate $^{\text {,178 }}$ in which to draw up a new treaty. Instead, the task should lie in strengthening existing regimes. A sense of integration and coordination amongst existing regimes needs to be achieved. In relation to this, Baird, Simons and Stephens note that the solution lies in the complicated task of 'ensuring that existing regimes are modified where necessary to embrace ocean acidification as a regime focus.' ${ }^{, 19}$

\footnotetext{
${ }^{174} \mathrm{H}$ Lamirande, 'From Sea to Carbon Cesspool: Preventing the World's Marine Ecosystems from Falling Victim to Ocean Acidification' (2011) 34 Suffolk Transnat'l LR 183, 205.

${ }^{175}$ Ibid, 207.

${ }^{176}$ Ibid, 209.

${ }^{177}$ Baird, Simons \& Stephens, above n 66, 463.

${ }^{178} \mathrm{Ibid}$.

${ }^{179}$ Ibid, 471.
} 
In navigating the various regimes that could be applied to ocean acidification, it is clear that there are various avenues that could be further modified to address the phenomenon. Adding to the problem is the 'treaty congestion' that already poses as major detraction, and which Weiss also observes, creates extra burdens at the national level in implementing international agreements. ${ }^{180}$ Nations require sufficient political, administrative, and economic capacity in order to successfully implement agreements. ${ }^{181}$ Thus, negotiating a new convention may add to this 'congestion', create an unnecessary duplication of responsibilities, and effectively prove to be an inappropriate solution.

Ultimately, it makes sense that the solution falls under the focus of one arrangement. This leads to the question: which arrangement is the most appropriate for dealing with ocean acidification? As the reduction of $\mathrm{CO}_{2}$ emissions, the major contributor of ocean acidification, is already the goal of the climate change regime, it is therefore put forward that this is the most appropriate forum for dealing with the phenomenon.

\subsection{Killing two birds with one stone: addressing ocean acidification under the UNFCCC?}

While ocean acidification is largely a marine issue, dealing with the problem of ocean acidification under UNCLOS may not be the most appropriate measure as no unequivocal marine pollution standard has been expressed under this regime. As mentioned earlier, potential ocean acidification harms might give rise to action under UNCLOS. This however provides a reactive approach, when a preventative approach is more appropriate and may be better provided for under the UNFCCC. ${ }^{182}$

Reducing and reversing the impacts of acidification could occur under the UNFCCC, as this convention addresses the root cause of the problem. States must commit to marked $\mathrm{CO}_{2}$ reductions, and the UNFCCC is the appropriate forum to put forward such a request. Placing the issue under the remit of the UNFCCC would allow states to delineate precisely what each party is expected to do to reduce the negative effects of ocean acidification. This is especially important, since the current mechanisms in place lack an overarching directing factor. Support for such a proposal has already been expressed in an inter-agency

\footnotetext{
${ }^{180}$ Weiss, above $\mathrm{n} 59,701$.

${ }^{181} \mathrm{Ibid}, 701-702$.

${ }^{182}$ UNFCCC, Art 2.
} 
report for the preparation of the UN Conference on Sustainable Development (Rio+20) in June 2012:

[UNFCCC] negotiations must consider not only the effect of increased levels of atmospheric carbon dioxide on the radiation balance of Earth but the negative impacts on ocean chemistry and ecosystems. Results of above 'tipping point' analyses should inform the setting of aggressive targets and schedules for [greenhouse gas] reduction through shifts to low carbon energy production. ${ }^{183}$

The UNFCCC allows for the establishment of ongoing regulatory processes, through the establishment of the COP to evaluation of the implementation of the UNFCCC and any associated instruments that the COP may adopt. ${ }^{184}$ Of notable relevance, the UNFCCC also requires the COP to:

Periodically examine the obligations of the parties and the institutional arrangements under the Convention, in the light of the objective of the Convention, the experience gained in its implementation and the evolution of scientific and technological knowledge. ${ }^{185}$

Indeed, scientific knowledge has evolved and ocean acidification is gaining increasing understanding within the IPCC. ${ }^{186}$ It is therefore reasonable to expect that the climate change regime would be modified to reflect this knowledge. Ocean acidification is a new challenge, and also a new facet of the problem of atmospheric pollution.

Issues remain within the climate change regime that would need to be addressed for it to adequately deal with acidification. These include:

1. ocean acidification is not expressly mentioned under the climate change regime;

2. accordingly, no specific carbon reduction target has been set for states to achieve in order to counteract the phenomenon;

\footnotetext{
${ }^{183}$ Intergovernmental Oceanographic Commission of the United Nations Educational, Scientific, and Cultural Organisation, International Maritime Organization, Food and Agriculture Organization \& United Nations Development Programme, A Blueprint for Ocean and Coastal Sustainability (2011) 32.

${ }^{184}$ UNFCCC, Art 7(2).

${ }^{185}$ Ibid, Art 7(2)(a) (empahasis added).

${ }^{186}$ Intergovernmental Panel on Climate Change, above n 15.
} 
3. the climate change regime encourages of the 'promotion, development and increased use' of questionable carbon dioxide sequestration technologies, ${ }^{187}$ such as ocean fertilisation;

4. the aggregation of the six greenhouse gases, allowing states to trade off greater reductions in some gases against lesser reductions in others, ${ }^{188}$ which allows the level of carbon emissions to stay the same or increase so long as other greenhouse gas levels are decreased.

Rather than adopting a new treaty on the issue, a new protocol to the UNFCCC could be adopted as a useful means to address the aforementioned issues. ${ }^{189}$ A new protocol is particularly essential since the first commitment period of the Kyoto Protocol ended in 2012. Accordingly, a new framework is required to be negotiated and ratified that can bring the emission reductions that the IPCC has indicated are needed. This would also provide a timely opportunity to incorporate ocean acidification within this protocol. Article 17 of the UNFCCC provides that the COP may, as they have done for the Kyoto Protocol, at 'any ordinary session, adopt protocols to the Convention.' ${ }^{190}$ The inclusion of such a provision highlights a sense of dynamism of the UNFCCC, and that it can respond flexibly to new knowledge and problems.

While extensive negotiations will no doubt be required, a new protocol can reap the benefits of following the UNFCCC and the useful tools and institutional machinery it has already established, for example, its decision-making processes, the IPCC, and its forum for ongoing discussion and negotiation. As Bodansky observes:

The framework convention-protocol approach allows states to address a problem in a step-by-step manner, rather than all at once. States tend to be willing to join a framework convention because it does not contain stringent obligations. As a result, they can begin to address a problem without waiting for a consensus to emerge on appropriate response measures. ${ }^{191}$

\footnotetext{
${ }^{187}$ Kyoto Protocol, Art 2(1)(a)(iv).

${ }^{188}$ Ibid, Art 3(1).

${ }^{189}$ This follows what some authors have described as, the 'framework convention-protocol approach', see: Bodansky, above n 58; G Ulfstein, 'International Framework for Environmental Decision-Making' in Fitzmaurice, Ong \& Merkouris (eds), above n 1, 26, 31.

${ }^{190}$ UNFCCC, Art 17.

${ }^{191}$ Bodansky, above n 58, 186.
} 
Ideally, a new protocol to the UNFCCC could introduce and define ocean acidification, acknowledge the harmful effects that rising ocean acidity has on marine life and water quality, and specify precise reduction targets for carbon emissions for states to achieve in order to mitigate these effects. Moreover, the new protocol would need to set out strategies for dealing with both ocean acidification and climate change, thus having the dual benefit of mitigating both of these phenomena. It could furthermore provide the architecture to guide existing regimes that touch upon ocean acidification, and also make recognition of its relationship with other regimes. As mentioned earlier, if a state were to bring a claim under Part XV of UNCLOS for climate change damages, the UNFCCC and Kyoto Protocol may have bearing in an overall decision of whether a state has taken sufficient measures to mitigate climate change. ${ }^{192} \mathrm{By}$ comparison, these treaties may not factor in an overall determination of whether a state has taken adequate measures to mitigate ocean acidification. However, if there were a new protocol that addresses ocean acidification, an express standard under international law to hold states to would then exist. Accordingly, it could be utilised as a criterion to assess the extent of a particular state's commitment to mitigating ocean acidification, if a claim were brought against them under UNCLOS.

With concerns surrounding carbon sequestration technologies in mind, it is submitted that a new protocol must urge states to take a precautionary approach, rather than explicitly encouraging the use of such technologies. The UNFCCC notes that '[p]arties should take precautionary measures to anticipate, prevent or minimize the causes of climate change and mitigate its adverse effects' ${ }^{193}$ A new protocol could contain similar phraseology, however with the inclusion of the words 'causes of ocean acidification'.

A new protocol to the UNFCCC needs to be geared towards mitigating the negative effects of ocean acidification, as well as climate change. It is essential that stabilisation targets for atmospheric $\mathrm{CO}_{2}$ based on ocean acidification be clearly defined in such a protocol, so that the phenomenon does not remain a peripheral concern. Scientists have already noted that atmospheric $\mathrm{CO}_{2}$ should be stabilised somewhere around 450 parts per million by volume or below in order to avoid the risk of large-scale disruptions in marine ecosystems. ${ }^{194}$ Setting out targets in relation to this will provide greater certainty about what needs to be achieved

\footnotetext{
${ }^{192}$ Doelle, above n 94, 326.

${ }^{193}$ UNFCCC, Art 3(3).

${ }^{194} \mathrm{~F}$ Joos et al, 'Impact of Climate Change Mitigation on Ocean Acidification Projections' in J Gattuso \& L Hansson (eds), Ocean Acidification (2011) 272, 288.
} 
by states. The UNFCCC provides the critical forum in which to establish these targets and to reinforce the need to reduce carbon emissions to prevent severe damage from ocean acidification.

In sum, a new protocol to address ocean acidification under the UNFCCC seems the most cogent step to take. The recommendations outlined above have been kept relatively general and no precise stabilisation targets have been clearly detailed. This is because this proposal obviously warrants further research and discussion on how to effectively prevent the negative effects of ocean acidification. Whatever regulatory path the international community decides to take, through a new protocol, the drafting of a new convention or the strengthening of existing regimes, increased actions are required to mitigate the threats that ocean acidification poses. The negative effects of ocean acidification are far too grave to be dealt with under the existing international law and policy framework.

\section{Conclusion}

This article has described the process and problems associated with ocean acidification. It has shown that the international law and policy applicable to the issue is incomplete and leaves uncertainty as to exactly how ocean acidification is to be prevented.

Returning to the beginning of this article, two important questions were asked. The first question was whether the current international regulatory framework provides adequate protection from the negative effects of ocean acidification. In light of the issues raised and conclusions drawn in Part III, the answer to this is that it does so only marginally. This is because ocean acidification still remains a peripheral concern across the different regimes, and thus, may lead to suboptimal environmental protection. While there is certainly a breadth of regulatory instruments that touch on the issue, they lack the necessary depth to adequately address it. The second question was whether, if these do not provide adequate protection, what else could be done to better address the issue. This paper has put forward that a new protocol under the UNFCCC, with a dedicated focus on ocean acidification, would be the most appropriate step.

Reduction targets for $\mathrm{CO}_{2}$ emissions need to be clearly set in a new protocol under the UNFCCC, to ensure that states understand precisely what is required of them in order to circumvent the negative consequences of ocean acidification. Such a protocol, with a parallel focus on both ocean acidification and climate 
change would provide an appropriate setting to adopt such targets. It would provide a crucial step that should be taken to break away from the 'treaty congestion', and to ensure that the burning issue of ocean acidification does not become lost amongst a sea of regimes. 